\title{
The Clinical Features and Prognosis of Nephrocalcinosis in Preterm Neonates : A Single Center Study in Korea
}

Hyunju Lee, M.D., So Yeon Shim, M.D., Eun Ae Park, M.D., and Su Jin Cho, M.D.

Department of Pediatrics, Ewha Womans University School of Medicine, Seoul, Korea

\section{ABSTRACT}

Purpose: Nephrocalcinosis (NC) is frequently observed in premature infants. Smallscale studies have suggested that NC adversely affects renal function; however, the etiologic factors are still unclear. This prospective observational study aimed to identify the factors that influence the development of $\mathrm{NC}$, through urine analysis.

Methods: In total, 99 preterm infants (gestational age $<34$ weeks) diagnosed with NC in the neonatal intensive care unit (NICU) from October 2010 to March 2014 were evaluated. Data regarding perinatal characteristics, respiratory support, total parenteral nutrition (TPN), and use of nephrotoxic drugs were analyzed. After an ultrasonographic diagnosis of NC, the infants were subjected to biweekly urine tests along with ultrasonographic follow-ups until the resolution of NC, in the outpatient department. Results: NC was diagnosed in 23\% (99/432) of the preterm infants admitted to the NICU. Their median gestational age and birth weight were $28^{+3}$ (range: $23^{+5}-35^{+2}$ ) weeks and 1,120 (range: 560-1,950) g, respectively. NC was diagnosed an average of $26.4 \pm 2.8$

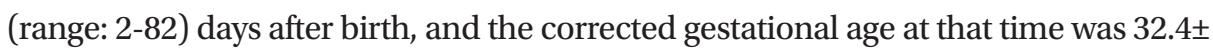
2.0 weeks. Preterm infants with NC had hyperoxaluria (oxalate/ $\mathrm{Cr}=4.1$ [oxalate $/ \mathrm{Cr}<$ $0.3]$ ), and low urinary citrate levels (citrate/Cr=0.03 [citrate/Cr $>0.51]$ ). The follow-up rate was $52 \%$ (27/52) and symptoms in none of the infants had progressed to nephrolithiasis. In the infants that were followed up, $\mathrm{NC}$ was resolved at a mean age of 7.7 (range: 2-32) months.

Conclusion: Our results suggest that hyperoxaluria is a significant risk factor for the development of NC.

Key Words: Nephrocalcinosis, Premature infants, Hyperoxaluria

\section{서론}

미숙아에서의 신석회화증(nephrocalcinosis)은 신장의 석회화로 정의되는데, 초음파에서 신장의 수질이나 피질에 밝은 반사체가 종단면과 횡단면에서 관찰되면 진단된다. Hufnagle 등 $^{1)}$ 은 미숙아에서 furosemide 치료를 장기간 받은 경우 신석회화증이 발생될 수 있음을 보 고하였다. 미숙아에서 신석회화증의 발생률은 7-41\%까지 다양하게 보고되고 있으며, 신석
Received: 15 October 2015

Revised: 29 June 2016

Accepted: 25 July 2016

Correspondence to: Su Jin Cho

Department of Pediatrics, Ewha

Womans University School of

Medicine, 911-1 Mok-dong, Yangcheon-gu, Seoul 07985, Korea

Tel: +82-2-2650-2845

Fax: +82-2-2653-3718

E-mail: sujin-cho@ewha.ac.kr
Copyright(c)

By Korean Society of Neonatology.

All right reserved.

This is an Open-Access article distributed under the terms of the Creative Commons Attribution Non-Commercial License (http://creativecommons.org/licenses/ by-nc/4.0), which permits unrestricted non-commercial use, distribution, and reproduction in any medium, provided the original work is properly cited. 
회화증의 발생에는 결석 억제 인자와 결석 촉진 인자와의 불균형 이 관여한다는 보고가 있다 ${ }^{2)}$. Furosemide의 사용 이외에도 낮 은 재태연령, 작은 출생체중 등이 잘 알려진 위험인자이고, FurOsemide나 dexamethasone의 사용 등으로 유발된 고칼슘뇨증이 신석회화증의 발생에 중요한 역할을 하고 있으며, 고수산뇨증과도 연관이 있다 ${ }^{2,3)}$.

신석회화증은 대부분 자연적으로 호전된다고 알려져 있으나 신 석증이나 요석증 등의 발생과 관련성이 보고되어 있고 ${ }^{4)}$, 신석회화 증이 있는 경우 장기 추적관찰에서 신기능이 저하되었다는 연구 결과가 있다 ${ }^{5,6)}$.

국내에서는 미숙아의 신석회화증의 위험인자에 대한 연구가 많 지 않아 ${ }^{7,8)}$, 미숙아에서 신석회화증의 발생과 연관된 요인에 대해 알아보고자 임상적 요인과 소변 검사 분석을 통해서 본 연구를 시 행하였다. 이후에 또한, 2 개월마다 신장초음파로 외래추적관찰을 시행하여 신석회화증의 경과가 어떠한지 살펴보고자 하였다.

\section{대상 및 방법}

\section{1. 대상}

2010년 10월부터 2014년 3월까지 이대목동병원 신생아 중환자 실(neonatal intensive care unit, NICU)에 입원한 34주 미만 출 생아 432명을 대상으로 하였다. 신석회화증의 진단은 신장 초음 파를 이용하였다. 전체 대상 환자 가운데 신장 초음파에서 신석 회화증이 진단된 군은 99명(23\%)이었다. 신석회화증이 진단되지 않은 군은 333명이었다. 4주 이내 사망하였거나 주요 선천성 기형 (major congenital anomaly)이 있는 경우는 제외하였다. 본원의 임상연구윤리위원회의 승인 하에 연구를 진행하였다.

\section{2. 영상진단}

신장 초음파는 생후 1 주 이내에 영상의학과 의사에 의해 시행되 었고, 신석회화증이 진단되지 않은 경우 2 주 후에 다시 검사를 시 행하였다. 신석회화증이 진단된 경우 1 주 후에 다시 검사를 시행 하였고, 외래에서 신석회화증이 회복될 때까지 2개월 간격으로 신 장 초음파로 추적관찰 하였다. 신석회화증은 신장의 수질이나 피 질에 밝은 반사체가 종단면과 횡단면에서 관찰되면 진단하였다.

\section{3. 자료수집}

임상 양상으로 재태연령, 출생체중, 5분 Apgar 점수, 산전 스테 로이드 사용(complete course와 incomplete course 모두 포함), 성별, 조기양막파수(premature rupture of membrane, PROM), 전자간증(pregnancy induced hypertension, PIH), 융모양막 염(chorioamnionitis) 등을 조사하였고, 입원 중에 이환된 질환
으로 신생아호흡곤란증후군(respiratory distress syndrome, $\mathrm{RDS}$ ), 기관지폐 이형성증(bronchopulmonary dysplasia, BPD), 간내담즙정체증(intrahepatic cholestasis, IHC)의 비율, 괴사 성 장염(necrotizing enterocolitis, NEC)의 유무, 뇌실내출혈 (intraventricular hemorrhage, IVH)의 유무 등이 조사되었다. 입 원 중에 받은 치료 중에서 인공호흡기 치료 비율 및 기간, 산소 치 료 비율 및 기간, 총정맥영양(total parenteral nutrition, TPN) 비 율 및 기간, 4주 이내에 한 번이라도 furosemide를 사용한 비율 및 사용량 등이 조사되었다. Furosemide는 유증상 동맥관 개존 증(significant patent ductus arteriosus)으로 인한 심장의 부하 증가, 수혈이나 알부민 투여 후 소변량 감소시 사용하였다.

조기양막파수는 질경 검사에서 질 내에 양수가 고여있거나 nitrazine test 양성인 경우로 진단하였고, 전자간증은 수축기 혈 압 $140 \mathrm{mmHg}$ 이상, 확장기 혈압 $90 \mathrm{mmHg}$ 이상이 최소한 6시 간 이상의 간격으로 2 회 이상 측정되었을 때, 단백뇨가 24 시간 채 취뇨에서 $300 \mathrm{mg}$ 이상이거나 6시간 이상의 간격을 두고 적어도 두 번의 채취뇨에서 $100 \mathrm{mg} / \mathrm{dl}$ 이상인 경우로 정의하였다. 융모양 막염은 제대와 태반을 $10 \%$ 포르말린에 고정 후 H\&E 염색을 실 시하고 병리과 판독결과 다형핵백혈구의 침윤을 관찰하여 진단 한 경우로 정의하였다. 신생아호흡곤란증후군은 임상적으로 호 흡 곤란 증세를 보이며 영상의학적으로 합당한 경우로 하였고 ${ }^{9}$, 기관지폐 이형성증은 Jobe와 Bancalari1 ${ }^{10)}$ 의 Modified criteria of bronchopulmonary dysplasia를 기준으로 하였다. 간내담즙정체 증은 직접 빌리루빈이 $2 \mathrm{mg} / \mathrm{dL}$ 이상인 경우로 정의하였다. 괴사 성 장염은 Bell의 기준에 의해 stage II 이상에 해당하는 경우로 정 의 하였고 ${ }^{11)}$, 뇌실내출혈은 Papile 등 ${ }^{12)}$ 의 분류에서 grade III 이상 으로 정의 하였다.

\section{4. 소변검사}

신석회화증이 진단되고 1주 이내에 소변 검사(spot urine)를 시 행하여 소변 크레아티닌, 소변 칼슘(정상: $\mathrm{Ca} / \mathrm{Cr}<0.86)^{13)}$, 소변 요 산(정상: $\mathrm{UA} / \mathrm{Cr}<2.38)^{14)}$, 소변 수산염(정상: oxalate $\left./ \mathrm{Cr}<0.175\right)^{14)}$, 소변 구연산염(정상: citrate/Cr>0.176) ${ }^{15)}$ 을 측정하였다.

\section{5. 통계분석}

두 군의 비교는 SPSS version 21.0 (IBM Co., Armonk, NY, USA)를 이용하여 Chi-square test, Fisher's exact test, $t$-test, Mann-Whitney $U$ test, Wilcoxon rank sum test로 하였다. 대상 환자의 수가 적어서 정규분포 가정이 어려워 중간값(범위)으로 위 험인자를 제시하였다. 단일 변수의 분석에서 두 군의 통계적으로 차이가 있고 임상적으로 의미가 있는 변수들을 이용해서 다변수 분석을 시행하였다. 모든 통계 수치는 $P<0.05$ 인 경우 통계적으로 의미가 있다고 보았다. 


\section{결과}

\section{1. 임상양상}

신석회화증은 NICU에 입원한 미숙아의 23\% (99/432)에서 진 단되었다. 신석회화증이 있는 군의 재태연령의 중간값은 $28^{+3}$ 주 (범위: $23^{+5}-35^{+2}$ 주), 출생체중의 중간값은 $1,120 \mathrm{~g}$ (범위: $560-$ $1,950 \mathrm{~g}$ ), 이었고, 신석회화증이 없는 군 보다 통계적으로 의미있 게 적었다. 5 분 Apgar 점수와 산전 스테로이드를 사용한 비율도 신석회화증이 있는 군에서 통계적으로 의미있게 적었다. 조기양 막파수의 발생은 신석회화증이 있는 군에서 통계적으로 의미있게 많았다. 남녀의 차이는 없었고(남 $49.5 \%$ ), 전자간증, 융모양막염의 발생에도 차이가 없었다(Table 1).

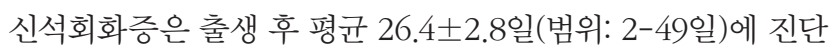

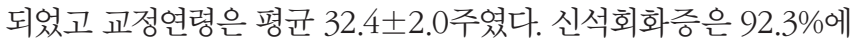
서 양측에 발생했다.

신생아호흡곤란증후군, 인공호흡기 치료 기간, 산소 치료 기간, 기관지폐 이형성증 유병률, 총정맥영양 기간은 신석회화증이 있 는 군에서 더 높았다 $(P<0.001)$. 총정맥영양 비율은 신석회화증이 없는 군에서 $90.4 \%$, 신석회화증이 있는 군에서 $97.0 \%$ 로 신석회 화증이 있는 군에서 더 높았다 $(P=0.023)$. 뇌실내출혈 비율은 신 석회화증이 없는 군에서 $5.1 \%$, 신석회화증이 있는 군에서 $16.2 \%$ 로 신석회화증이 있는 군에서 더 높았다 $(P=0.001)$. 4 주 이내의 furosemide 사용량은 신석회화증이 없는 군에서 중간값 $0 \mathrm{mg} /$ $\mathrm{kg}$ (범위:0-26), 신석회화증이 있는 군에서 중간값 $2 \mathrm{mg} / \mathrm{kg}$ (범 위: 0-32)으로 신석회화증이 있는 군에서 더 높았다 $(P<0.001) .4$ 주 이내의 furosemide 사용 비율은 신석회화증이 없는 군에서 $32.1 \%$, 신석회화증이 있는 군에서 $67.7 \%$ 로 신석회화증이 있는 군

Table 1. Clinical Characteristics and Nephrocalcinosis

\begin{tabular}{lccc}
\hline & $\begin{array}{c}\text { Nephrocalcinosis } \\
(-)(\mathrm{n}=333)\end{array}$ & $\begin{array}{c}\text { Nephrocalcinosis } \\
(+)(\mathrm{n}=99)\end{array}$ & $\begin{array}{c}P \text { - } \\
\text { value }\end{array}$ \\
\hline Gestational age (wks) & $32\left(23-34^{+2}\right)$ & $28^{+3}\left(23^{+5}-35^{+2}\right)$ & $<0.001$ \\
Birth weight (g) & $1,700(350-2,760)$ & $1,120(560-1,950)$ & $<0.001$ \\
Apgar score, 5 min & $8(0-10)$ & $8(3-10)$ & $<0.001$ \\
Antenatal steroid (\%) & 63.1 & 26.3 & $<0.001$ \\
Male (\%) & 59.2 & 49.5 & 0.056 \\
PROM (\%) & 27.3 & 40.4 & 0.010 \\
PIH (\%) & 12.9 & 13.1 & 0.536 \\
Chorioamnionitis (\%) & 28.3 & 29.3 & 0.471 \\
\hline
\end{tabular}

Data are presented as median (range) for continuous data and n (\%) for dichotomous data.

* $P$-value for Wilcoxon rank sum test.

Abbreviations: PROM, premature rupture of membrane; PIH, pregnancyinduced hypertension.
에서 더 높았다 $(P<0.001)$. 괴사성 장염, 뇌실내출혈의 발생에는 차이가 없었다(Table 2).

\section{2. 다변량 분석}

출생 체중을 보정한 다변량 분석에서 5분 Apgar 점수가 신석회 화증의 위험인자로 나타났고, 산전 스테로이드의 사용이 신석회 화증의 방어인자로 나타났다(Table 3).

\section{3. 소변 검사}

신석회화증이 있는 미숙아의 소변 칼슘 $(\mathrm{Ca} / \mathrm{Cr}=0.8 \pm 0.2)$ 및

Table 2. Neonatal Outcome and Nephrocalcinosis

\begin{tabular}{lccc}
\hline & $\begin{array}{c}\text { Nephrocalcinosis } \\
(-)(\mathrm{n}=333)\end{array}$ & $\begin{array}{c}\text { Nephrocalcinosis } \\
(+)(\mathrm{n}=99)\end{array}$ & $\begin{array}{c}P \text { - } \\
\text { value }\end{array}$ \\
\hline RDS (\%) & 46.2 & 78.8 & $<0.001$ \\
$\begin{array}{l}\text { Duration of ventilator } \\
\text { care (d) }\end{array}$ & $1(0-123)$ & $22(0-101)$ & $<0.001$ \\
Duration of oxygen & $6(0-156)$ & $54(0-185)$ & $<0.001$ \\
$\quad$ use (d) & & & \\
BPD (\%) & 14.2 & 57.6 & $<0.001$ \\
TPN duration (d) & $10(0-128)$ & $23(0-100)$ & $<0.001$ \\
TPN (\%) & 90.4 & 97.0 & 0.023 \\
IHC (\%) & 5.1 & 16.2 & 0.001 \\
Furosemide within 4 & $0(0-26)$ & $2(0-32)$ & $<0.001$ \\
weeks (mg/kg) & & & \\
Use of furosemide & 32.1 & 67.7 & $<0.001$ \\
within 4 weeks (\%) & & & \\
NEC (\%) & 2.1 & 5.1 & 0.115 \\
IVH (\%) & 3.0 & 5.1 & 0.244 \\
\hline
\end{tabular}

Data are presented as median (range) for continuous data and n (\%) for dichotomous data.

${ }^{*} P$-value for Wilcoxon rank sum test.

Abbreviations: RDS, respiratory distress syndrome; BPD, bronchopulmonary dysplasia; TPN, total parenteral nutrition; IHC, intrahepatic cholestasis; NEC, nectrotizing enterocolitis; IVH, intraventricular hemorrhage.

Table 3. Multivariable Model for Prediction of Nephrocalcinosis

\begin{tabular}{lcc}
\hline Factor & OR $(95 \% \mathrm{CI})$ & $P$-value \\
\hline Birth weight & $0.998(0.997-0.999)$ & $<0.0001$ \\
Apgar score $5 \mathrm{~min}$ & $1.412(1.133-1.758)$ & 0.002 \\
Use of antenatal steroids & $0.154(0.080-0.295)$ & $<0.0001$ \\
Use of oxygen (d) & $1.032(1.019-1.046)$ & $<0.0001$ \\
TPN duration (d) & $0.974(0.956-0.993)$ & 0.007 \\
Furosemide within 4 weeks $(\mathrm{mg} / \mathrm{kg})$ & $1.090(0.991-1.198)$ & 0.075
\end{tabular}

Abbreviations: OR, odds ratio; CI, confidence interval; TPN, total parenteral nutrition. 


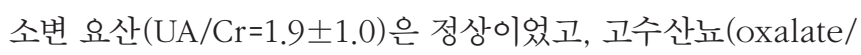

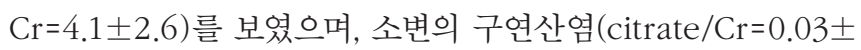
0.06)은 낮았다(Table 4).

\section{4. 예후}

추적관찰률은 $52 \%$ (27/52)였다. 신석회화증이 처음 진단된 시 기는 평균 $32.4 \pm 2$ 주(생후 $26.4 \pm 2.8$ 일)였고, 소실된 시기는 평균 $7.7 \pm 6.2$ (범위: 2-32)개월이었으며, 신석증(nephrolithiasis)은 없 었다(Table 5).

\section{고찰}

본 연구에서 신석회화증은 NICU에 입원한 미숙아의 23\% (99/ 432)에서 진단되었다. 최근의 연구들에 따르면 신석회화증의 발생 률은 16-27\%로 다양하게 보고되고 있다 ${ }^{3,16-18)}$. 최근에 발표된 연 구들에서 신석회화증의 발생률이 감소하고 있는데, 신생아 중환 자 치료 방법의 발전으로 위험 인자에 대한 노출이 감소되고 있기 때문으로 보인다 ${ }^{8,16)}$.

신석회화증의 발생에 관련되어 있다고 알려진 위험인자에는 낮 은 재태연령, 작은 출생 체중, 남성, 장기간의 총정맥영양, 장기간의 산소 사용, furosemide의 사용, 산전 또는 산후 스테로이드 사용 등이 있다 ${ }^{16-21)}$. Alon 등 르의 연구에서 쥐를 대상으로 furosemide 를 각각 2 주와 8 주 동안 투여한 결과 신석회화증이 발생하였고, 두 군 간의 차이는 없었다. Osorio 등 ${ }^{23)}$ 의 연구에서 생후 4 주, 6 주, 10 주인 쥐를 대상으로 furosemide를 고용량 $(40 \mathrm{mg} / \mathrm{kg})$ 투여하

Table 4. Urine Chemistry in Nephrocalcinosis

\begin{tabular}{lcl}
\hline & $\begin{array}{c}\text { Nephrocalcinosis } \\
(+)(\mathrm{n}=99) \\
\text { mean }(\text { range })\end{array}$ & $\begin{array}{c}\text { Normal } \\
\text { values }\end{array}$ \\
\hline Urine Calcium/Creatinine $(\mathrm{mg} / \mathrm{mg})$ & $0.8 \pm 0.2(0-3.6)$ & $<0.86^{9)}$ \\
Urine Uric Acid/Creatinine $(\mathrm{mg} / \mathrm{mg})$ & $1.9 \pm 1.0(0.1-3.8)$ & $<2.38^{10)}$ \\
Urine Oxalate/Creatinine $(\mathrm{mg} / \mathrm{mg})$ & $4.1 \pm 2.6(0.1-35.5)$ & $<0.175^{10)}$ \\
Urine Citrate/Creatinine $(\mathrm{mg} / \mathrm{mg})$ & $0.03 \pm 0.06(0-1.00)$ & $>0.176^{11)}$ \\
\hline
\end{tabular}

Table 5. Clinical Outcome of Nephrocalcinosis

\begin{tabular}{lc}
\hline & $\begin{array}{c}\text { Nephrocalcinosis } \\
(+)(\mathrm{n}=99)\end{array}$ \\
\hline Time of diagnosis, mean (range) & $32.4 \pm 2$ weeks GA (23.9-39.7) \\
& $26.4 \pm 2.8$ days after birth (2-82) \\
Time of disappearance on & $7.7 \pm 6.2(2-32)$ \\
US (months), mean (range) & 0 \\
Nephrolithiasis & 0 \\
\hline
\end{tabular}

Abbreviations: GA, gestational age; US, ultrasonography
고 14일 뒤에 관찰한 결과 쥐의 연령에 따른 차이 없이 신석회화 증이 발생하였고, 신장의 석회화의 발생은 furosemide의 투여 후 3-5일 사이에 최대인 것으로 나타났다. 본 연구에서는 낮은 재태 연령, 작은 출생 체중, 낮은 5분 Apgar 점수, 장기간의 총정맥영양, 장기간의 산소 사용 등이 신석회화증의 발생에 관련된 인자로 나 타났고, 출생 체중을 보정한 다변량 분석에서 5 분 Apgar 점수가 신석회화증의 위험인자로 나타났다.

Narendra 등 ${ }^{16)}$ 의 연구에서 신석회화증이 있는 16 명의 미숙아 에서 소변 수산과 소변 요산이 대조군에 비해 높게 나타났으나 소 변 칼슘에서는 차이가 없었다. Schell-Feith 등긔 의 연구에서 신석 회화증이 있는 88 명의 미숙아에서 소변검사를 시행한 결과 소변 칼슘과 소변 수산의 증가가 보고되었다. Sikora 등 ${ }^{24)}$ 의 연구에서 신석회화증이 있는 16 명의 극소저체중출생아를 분석한 결과 소변 구연산염의 감소가 관찰되었고 9명에서 소변 칼슘/구연산염 비의 증가가 있었다. 본 연구에서는 신석회화증이 있는 미숙아에서 소 변 칼슘과 소변 요산은 정상이었고, 소변 수산의 증가 및 소변 구 연산염의 감소가 나타났다.

McCormick 등 ${ }^{25)}$ 의 연구에서 신석회화증이 있는 환자의 신장 부검에서 세뇨관 내에 수산칼슘의 침착이 관찰되었다. 신석회화 증이 있는 미숙아에서 소변 수산이 증가가 나타났고, 소변 수산의 증가가 신석회화증의 결석 촉진 인자 중의 하나로 작용 한다는 보 고가 있다 ${ }^{16,17)}$. Campfield와 $\operatorname{Braden}^{26)}$ 의 연구에서 미숙아의 총정 맥영양으로 수산의 전구체인 아스코르브산(ascorbic acid)과 글 라이신(glycine)이 포함되는데, 총정맥영양을 시행한 미숙아에서 포도당과 전해질 용액을 투여한 대조군에 비해서 소변 수산이 증 가된 것이 보고 되었다. Campfield 등ㄱㅇㅢ 의년게서 분유를 먹인 미숙아에서 모유를 먹인 군에서 보다 소변 수산이 증가되었는데, 아스코르브산의 농도가 모유보다 분유에서 높기 때문인 것으로 보인다. 다른 이유로 분유를 먹인 미숙아에서 모유를 먹인 경우 보 다 지방산의 흡수가 저해되는데 흡수되지 않은 지방이 칼슘과 결 합하여 수산칼슘의 생성이 감소되고 수산나트륨의 생성이 증가된 다. 수산나트륨은 수산칼슘 보다 장내 흡수가 잘 되므로 수산의 흡수가 증가되어 소변에서의 수산 배출도 증가 될 수 있다 ${ }^{27,28)}$.

신석회화증은 소변 칼슘, 수산, 요산 등의 결석 촉진 인자와 소 변 구연산염, 마그네슘 등의 결석 억제 인자와의 불균형이 원인이 라는 연구 결과가 있다 ${ }^{17)}$. 구연산염은 수산칼슘 결정의 형성을 저 해하여 결석을 억제하는 효과가 있다 ${ }^{29-32}$. Schell-Feith 등 ${ }^{33)}$ 의 연 구에서 38 명의 미숙아를 대상으로 $0.52 \mathrm{mmol} / \mathrm{kg} / \mathrm{day}$ 의 sodium citrate를 투여한 결과 소변 구연산염의 유의한 증가와 소변 칼슘/ 구연산염 비의 의미있는 감소가 있었고, 부작용도 없었으나 신석 회화증의 발생에는 대조군과의 차이가 없었다. 신석회화증을 예 방하기 위한 구연산염의 투여에 대한 추가적인 연구가 필요할 것 으로 보인다. 
본 연구에서는 추적관찰에서 평균 $7.7 \pm 6.2$ 개월에 신석회화증 이 소실 되었고, 신석증은 관찰되지 않았다. Ezzedeen 등 $^{34}$ 의 연 구에서 신생아 때 신석회화증이 있었던 9명을 추적관찰한 결과 이 중 4 명에서 신석회화증의 완전한 소실이 관찰되었다. Porter 등 ${ }^{35)}$ 의 연구에서 신생아 때 신석회화증이 있었던 12명을 5-7세까 지 추적 관찰한 결과 9명에서는 신석회화증의 소실이 관찰되었다. Downing 등 ${ }^{4}$ 의 연구에서 신석회화증 환자에서 요석증의 발생이 보고되었고, Schell-Feith 등 ${ }^{36)}$ 의 연구에서 83 명의 신석회화증 환 자를 추적 관찰한 결과 요석증은 관찰되지 않았다.

본 연구에서는 다루지 않았으나, Kist-van Holthe 등 ${ }^{5}$ 의 연구 에서 신석회화증이 있었던 미숙아와 신석회화증이 없었던 미숙아 의 혈압은 정상보다 높은 경향이 있었으나 신석회화증 있었던 군 과 없었던 군 사이에 차이는 없었다. Giapros 등 ${ }^{377}$ 의 연구에서 신 석회화증이 있었던 63명에서 신석회화증이 없었던 대조군 44명 에 비해 신장 길이(kidney length)가 짧은 것으로 보고되었다.

Ezzedeen 등 ${ }^{34)}$ 의 연구에서 신생아 때 신석회화증이 있었던 9 명을 추적관찰한 결과 이 중 4명에서 사구체여과율(glomerular filtration rate)의 이상이 보고되었다. Kist-van Holthe 등 ${ }^{5}$ 의 연 구에서 신생아 때 신석회화증이 있었던 40명 중 6명(15\%)에서 사 구체여과율의 감소가 관찰되었고, 신석회화증이 없었던 32 명 중 에서는 2 명(6\%)에서 사구체여과율이 감소되었다. Jones 등 ${ }^{6}$ 의 연 구에서 신생아 때 신석회화증이 있었던 11명을 분석한 결과 사구 체여과율의 이상은 보고되지 않았다. Giapros 등 ${ }^{37}$ 의 연구에서 신석회화증이 있었던 63명에서 신석회화증이 없었던 대조군에 비 해 사구체여과율의 차이는 관찰되지 않았고, Saarela 등 ${ }^{38)}$ 의 연구 에서도 신석회화증이 있었던 20명과 신석회화증이 없었던 20명 에서 사구체여과율의 차이는 관찰되지 않았다. 향후 이에 대한 연 구가 필요할 것으로 보인다.

Schell-Feith 등 ${ }^{36)}$ 의 연구와 Saarela 등 ${ }^{38)}$ 의 연구에서 신석회화 증이 있는 군을 추적관찰한 결과 신세뇨관 기능의 이상이 보고되 었으나 신세뇨관 기능의 이상과 신석회화증과의 연관성이 확실히 밝혀지지는 않았다. Giapros 등 ${ }^{37)}$ 의 연구에서 신석회화증이 있었 던 63명에서 신석회화증이 없었던 대조군에 비해 세뇨관 기능의 이상이 보고되었다.

본 연구의 제한점은 신석회화증이 진단된 환자에서만 소변검사 를 시행하였고, 신석회화증이 없는 환자에서 소변검사를 시행하 지 못한 것이다. 또한 단일 기관에서 시행되었고 대상 환자의 수가 적어서 분석에 제한점이 있었다.

신석회화증의 선별검사는 NICU 입원 셋째 주 정도에 추천되며, 신기능과 초음파를 퇴원 후에도 장기적으로 추적관찰 해야 한다. 우리의 결과에서 고수산뇨가 신석회화증의 발생에 의미 있는 위 험 요인으로 밝혀졌다. 총정맥영양에서 구연산염을 사용하는 것 은 고수산뇨가 생기는 것을 방해하기 때문에 고위험군 미숙아에
게 도움이 될 것으로 생각되나 실제 임상연구를 통해 확인이 필요 하겠다.

\section{REFERENCES}

1) Hufnagle KG, Khan SN, Penn D, Cacciarelli A, Williams P. Renal calcifications: a complication of long-term furosemide therapy in preterm infants. Pediatrics 1982;70:360-3.

2) Schell-Feith EA, Kist-van Holthe JE, van der Heijden AJ. Nephrocalcinosis in preterm neonates. Pediatr Nephrol 2010; 25:221-30.

3) Hein G, Richter D, Manz F, Weitzel D, Kalhoff H. Development of nephrocalcinosis in very low birth weight infants. Pediatr Nephrol 2004;19:616-20.

4) Downing GJ, Egelhoff JC, Daily DK, Thomas MK, Alon U. Kidney function in very low birth weight infants with furosemide-related renal calcifications at ages 1 to 2 years. J Pediatr 1992;120:599-604.

5) Kist-van Holthe JE, van Zwieten PH, Schell-Feith EA, Zonderland HM, Holscher HC, Wolterbeek R, et al. Is nephrocalcinosis in preterm neonates harmful for long-term blood pressure and renal function? Pediatrics 2007;119:468-75.

6) Jones CA, King S, Shaw NJ, Judd BA. Renal calcification in preterm infants: follow up at 4-5 years. Arch Dis Child Fetal Neonatal Ed 1997;76:F185-9.

7) Park MJ, Park KI, Park MS, Namgung R, Lee C, Han DG, et al. Furosemide-induced nephrocalcinosis in very low birth weight infants. J Korean Pediatr Soc 1994;37:553-9.

8) Shim GH, Lee JA, Shin YJ, Kim EK, Park JD, Kim BI, et al. Risk factors of nephrocalcinosis in very low birth weight(VLBW) infants. Korean J Pediatr 2004;47:275-81.

9) Rudolph AJ, Smith CA. Idiopathic respiratory distress syndrome of the newborn: an international exploration. J Pediatr 1960;57:905-21.

10) Jobe AH, Bancalari E. Bronchopulmonary dysplasia. Am J Respir Crit Care Med 2001;163:1723-9.

11) Bell MJ, Ternberg JL, Feigin RD, Keating JP, Marshall R, Barton $\mathrm{L}$, et al. Neonatal necrotizing enterocolitis. Therapeutic decisions based upon clinical staging. Ann Surg 1978;187:1-7.

12) Papile LA, Burstein J, Burstein R, Koffler H. Incidence and evolution of subependymal and intraventricular hemorrhage: a study of infants with birth weights less than 1,500 gm. J Pediatr 1978;92:529-34.

13) Sargent JD, Stukel TA, Kresel J, Klein RZ. Normal values for random urinary calcium to creatinine ratios in infancy. J Pediatr 1993;123:393-7.

14) Matos V, Van Melle G, Werner D, Bardy D, Guignard JP. Uri- 
nary oxalate and urate to creatinine ratios in a healthy pediatric population. Am J Kidney Dis 1999;34:e1.

15) Srivastava T, Winston MJ, Auron A, Alon US. Urine calcium/ citrate ratio in children with hypercalciuric stones. Pediatr Res 2009;66:85-90.

16) Narendra A, White MP, Rolton HA, Alloub ZI, Wilkinson G, $\mathrm{McColl} \mathrm{JH,} \mathrm{et} \mathrm{al.} \mathrm{Nephrocalcinosis} \mathrm{in} \mathrm{preterm} \mathrm{babies.} \mathrm{Arch} \mathrm{Dis}$ Child Fetal Neonatal Ed 2001;85:F207-13.

17) Schell-Feith EA, Kist-van Holthe JE, Conneman N, van Zwieten PH, Holscher HC, Zonderland HM, et al. Etiology of nephrocalcinosis in preterm neonates: association of nutritional intake and urinary parameters. Kidney Int 2000;58: 2102-10.

18) Gimpel C, Krause A, Franck P, Krueger M, von Schnakenburg C. Exposure to furosemide as the strongest risk factor for nephrocalcinosis in preterm infants. Pediatr Int 2010;52:51-6.

19) Hoppe B, Hesse A, Neuhaus T, Fanconi S, Blau N, Roth B, et al. Influence of nutrition on urinary oxalate and calcium in preterm and term infants. Pediatr Nephrol 1997;11:687-90.

20) Hoppe B, Hesse A, Neuhaus T, Fanconi S, Forster I, Blau N, et al. Urinary saturation and nephrocalcinosis in preterm infants: effect of parenteral nutrition. Arch Dis Child 1993;69: 299-303.

21) Cranefield DJ, Odd DE, Harding JE, Teele RL. High incidence of nephrocalcinosis in extremely preterm infants treated with dexamethasone. Pediatr Radiol 2004;34:138-42.

22) Alon US, Kaplan RA, Gratny LL, Nichols MA. Histological long-term outcome of furosemide-induced nephrocalcinosis in the young rat. Pediatr Nephrol 1996;10:191-4.

23) Osorio AV, Alon MM, Nichols MA, Alon US. Effect of age on furosemide-induced nephrocalcinosis in the rat. Biol Neonate 1998;73:306-12.

24) Sikora P, Roth B, Kribs A, Michalk DV, Hesse A, Hoppe B. Hypocitraturia is one of the major risk factors for nephrocalcinosis in very low birth weight (VLBW) infants. Kidney Int 2003;63:2194-9.

25) McCormick FC, Brady K, Keen CE. Oxalate nephrocalcinosis: a study in autopsied infants and neonates. Pediatr Pathol Lab Med 1996;16:479-88.

26) Campfield T, Braden G. Urinary oxalate excretion by very low birth weight infants receiving parenteral nutrition. Pediatrics
1989;84:860-3.

27) Campfield T, Braden G, Flynn-Valone P, Clark N. Urinary oxalate excretion in premature infants: effect of human milk versus formula feeding. Pediatrics 1994;94:674-8.

28) Earnest DL. Enteric hyperoxaluria. Adv Intern Med 1979;24: 407-27.

29) Berg C, Larsson L, Tiselius HG. The effects of a single evening dose of alkaline citrate on urine composition and calcium stone formation. J Urol 1992;148:979-85.

30) Barcelo P, Wuhl O, Servitge E, Rousaud A, Pak CY. Randomized double-blind study of potassium citrate in idiopathic hypocitraturic calcium nephrolithiasis. J Urol 1993;150:1761-4.

31) Hauser W, Frick J, Kunit G. Alkali citrate for preventing recurrence of calcium oxalate stones. Eur Urol 1990;17:248-51.

32) Pak CY, Fuller C, Sakhaee K, Preminger GM, Britton F. Longterm treatment of calcium nephrolithiasis with potassium citrate. J Urol 1985;134:11-9.

33) Schell-Feith EA, Moerdijk A, van Zwieten PH, Zonderland HM, Holscher HC, Kist-van Holthe J, et al. Does citrate prevent nephrocalcinosis in preterm neonates? Pediatr Nephrol 2006; 21:1830-6.

34) Ezzedeen F, Adelman RD, Ahlfors CE. Renal calcification in preterm infants: pathophysiology and long-term sequelae. J Pediatr 1988;113:532-9.

35) Porter E, McKie A, Beattie TJ, McColl JH, Aladangady N, Watt A, et al. Neonatal nephrocalcinosis: long term follow up. Arch Dis Child Fetal Neonatal Ed 2006;91:F333-6.

36) Schell-Feith EA, Kist-van Holthe JE, van Zwieten PH, Zonderland HM, Holscher HC, Swinkels DW, et al. Preterm neonates with nephrocalcinosis: natural course and renal function. Pediatr Nephrol 2003;18:1102-8.

37) Giapros V, Tsoni C, Challa A, Cholevas V, Argyropoulou M, Papadopoulou F, et al. Renal function and kidney length in preterm infants with nephrocalcinosis: a longitudinal study. Pediatr Nephrol 2011;26:1873-80.

38) Saarela T, Lanning P, Koivisto M. Prematurity-associated nephrocalcinosis and kidney function in early childhood. Pediatr Nephrol 1999;13:886-90. 